\title{
Engineering of functionalized carbon nano-onions reinforced nanocomposites: Fabrication, biocompatibility, and mechanical properties
}

\author{
Narsimha Mamidii, a) (D), Marcelo Renato Martínez Gamero', Ramiro Manuel Velasco \\ Delgadilloº ${ }^{1}$ Javier Villella Castrejón ${ }^{1}$, Alex Elías Zúníga ${ }^{1}$ \\ ${ }^{1}$ Department of Chemistry and Nanotechnology, Tecnologico de Monterrey, School of Engineering and Science, Monterrey, Nuevo Leon 64849, Mexico \\ ${ }^{a}$ Address all correspondence to this author. e-mail: nmamidi@tec.mx \\ This paper has been selected as an Invited Feature Paper.
}

Received: 21 August 2019; accepted: 7 January 2020

Poly 4-mercaptophenyl methacrylate-carbon nano-onions ((PMPMA-CNOs $=\mathrm{f}-\mathrm{CNOs})$ were reinforced with polycaprolactone $(\mathrm{PCL})$ to produce $\mathrm{PCL} / \mathrm{f}-\mathrm{CNO}$ nanocomposites using probe sonication. The physicochemical properties of nanocomposites were systematically studied to analyze cell viability and proliferation. In vitro cytotoxicity of PCL/f-CNO nanocomposites was measured with osteoblast cells, and improved cell viability was observed. The cytotoxicity of f-CNOs to osteoblasts was dose-dependent, and PCL/f-CNO (0.5 wt\%) nanocomposites showed more than $90 \%$ of viability as compared to pristine PCL. Similarly, PCL/f-CNO (0.5 wt\%) nanocomposites showed substantial enhancement in mechanical properties. The yield strength, tensile strength, Young modulus, elastic modulus, and fracture toughness were also upgraded at high content of f-CNOs ( 0.5 wt\%). The concentration of $\mathrm{f}-\mathrm{CNO}$ considerably influenced the strengthening of PCL/f-CNO nanocomposites, which shows its degree of colloidal dispersion stability and extent of polymer wrapping within the PCL matrix. Nevertheless, these nontoxic PCL/f-CNO nanocomposites can be used as promising biomaterials for orthopedic applications.

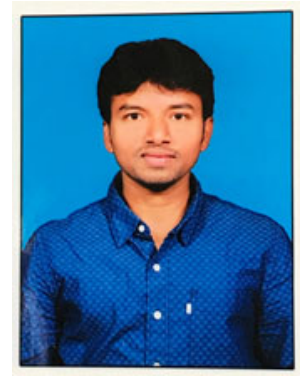

Narsimha Mamidi

\begin{abstract}
Dr. Narsimha Mamidi received his B.Sc. in chemistry from the Osmania University, in 2006 and M.Sc. in organic chemistry from Kakatiya University, Warangal, India, in 2008. He then moved to the Indian Institute of Technology Guwahati, India, for Ph.D. (Organic Chemistry) in 2009. During his Ph.D., he designed and synthesized various novel biological organic molecules and investigated their interactions with protein kinase C (PKC). In October 2014, he received Ph.D. from the Indian Institute of Technology Guwahati, India. Dr. Mamidi has received 2014-Eli-Lilly Outstanding Thesis Award for his Ph.D. research. He then moved to the Indian Institute of Technology Mandi, India, where from 09/2014 to 09/2015 he was a postdoctoral fellow. During his postdoc, he developed novel photoresist and bioresist materials and investigated their lithography studies to achieve below 16-nm size patterning. Currently, Dr. Mamidi is working as a postdoctoral researcher at the school of engineering and science, Tecnologico de Monterrey, Mexico. His current research interest is focused on the rational design and development of bio/nanomaterials for biomedical, catalysis, sensing, and energy storage applications.
\end{abstract}

\section{Introduction}

Biodegradable medical-grade biomaterials have received immense attention in recent times due to their potential applications as cardiovascular interventional devices and orthopedic implants [1, 2]. The most commonly used materials for bone fracture fixation are $316 \mathrm{~L}$ stainless steel, cobalt-chromiumbased alloys, titanium alloys, and various polymers $[3,4]$. The foremost desirable characteristic of implantable materials is their degradability after the bone has healed. However, the above metals are nondegradable, and cause the risk of local inflammation and, hence, premature replacement of implants [5]. Therefore, biodegradable polymers have been investigated to reduce such complications [6]. In this context, polymer-based biodegradable biomaterials including poly(lactic-co-glycolic acid) 
(PLGA), poly(L-lactic acid) (PLA), and polycaprolactone (PCL) have been extensively used in clinics to benefit with the renovation of human tissues, for instance as absorbable bone plates, pins, and bone screws [7,8]. Among these polymers, PCL is a promising biodegradable polymer due to its great biocompatibility, significant toughness, and outstanding tensile properties ( $80 \%$ of elongation at a breakpoint) $[5,9]$. PCL is a semicrystalline polymer that has higher fracture energy and a sluggish degradation rate than most biopolymers $[9,10]$. In addition, the hydrophobic nature of PCL is more appropriate for a coating applied on metal alloys $[5,11]$. However, PCL has some detriments when used alone due to a lack of desired biocompatibility and insufficient strength $[7,11]$. Therefore, it is important to overcome these drawbacks, which can be accomplished by using appropriate second-phase reinforcement. For instance, most of the biopolymers including PCL are reinforced with nanofillers, such as graphite (Gr), carbon fibers (CF), graphite fluoride (CFx), carbon nanotubes (CNTs), graphene oxide (GO), and hydroxyapatite (HA), to improve their mechanical properties and biocompatibility $[9,11,12,13$, 14].

Among carbon fillers, CNTs are considered to be ideal reinforcing nanofillers for polymer matrices because of their unique structure and properties [15]. However, CNTs display different levels of toxicity based on their shape, size, surface area to volume ratio, synthetic methods, and extent of oxidation [13, 16]. Besides, CNTs can extend their toxicity through protein synthesis, oxidative stress, mitochondrial amendments, intramolecular metabolic paths, apoptosis, and necrosis [17]. However, graphene and its derivative affect the plasma membrane, membrane organelles, and cytoskeleton (e.g., lysosomes, nucleus, and mitochondrion) [18]. Therefore, it is highly appropriate to develop a facile method to fabricate nontoxic carbon-based nanocomposites with improved mechanical properties and biocompatibility.

Carbon nano-onions (CNOs) are a new member of carbonaceous materials, which were first described by Ugarte in 1992 [19]. Because of their inimitable physicochemical properties, CNOs have been used in numerous research fields, including catalysis, lithium-ion battery, supercapacitor, therapeutic, cell imaging, diagnostic, and biomedical applications $[20,21,22,23,24,25]$. The toxicity of CNOs was systematically measured and they were found to be more biocompatible than MWCNTs with benign inflammatory response [24]. Also, pristine CNOs, oxidized CNOs, and PEGylated CNOs were found to be nontoxic and showed excellent cell viability with fibroblasts [26].

Recently, poly 4-mercaptophenyl methacrylate-CNOs (PMPMA-CNOs $=\mathrm{f}-\mathrm{CNOs}$ ) were synthesized and reinforced with ultra-high molecular weight polyethylene (UHMWPE) to engineer UHMWPE/f-CNO nanocomposites [27]. The physicochemical properties and cytotoxicity of UHMWPE/fCNO nanocomposites were systematically studied. These composites exhibited good cell growth, adhesion, and viability with osteoblast cells. Besides, the nanocomposites showed improved tensile strength (83\%) compared to pure UHMWPE. In addition, f-CNOs were reinforced with zein protein to develop zein/f-CNO composite hydrogels for $\mathrm{pH}$-responsive controlled drug release [28]. The zein/f-CNO composite hydrogels showed improved mechanical properties and cytocompatibility [28]. These results of CNOs motivated us to fabricate PCL/ CNO nanocomposites as alternate biomaterials for orthopedic applications.

Nevertheless, to the best of our knowledge, the development of $\mathrm{f}-\mathrm{CNO}$ reinforced $\mathrm{PCL} / \mathrm{f}-\mathrm{CNO}$ nanocomposites has not yet been reported. Consequently, it was hypothesized that f-CNOs could be uniformly dispersed and reinforced homogeneously within the PCL matrix. Good colloidal dispersion of f-CNO particles can improve the tensile properties, biodegradability, and biocompatibility of PCL/f-CNO nanocomposites.

In the current study, $\mathrm{f}-\mathrm{CNO}$ reinforced $\mathrm{PCL} / \mathrm{f}-\mathrm{CNO}$ nanocomposites were manufactured using probe sonication followed by hydraulic pressing. Two different weight percentages (0.2 and $0.5 \mathrm{wt} \%$ ) of $\mathrm{f}-\mathrm{CNO}$ were used to develop PCL/f-CNO nanocomposites. Considering the high surface area of CNOs, the weight percentage of $\mathrm{f}$-CNOs was kept very low. Thermal, mechanical, and cytotoxicity assessments of PCL/f-CNO nanocomposites were explored systematically. Young's modulus, tensile strength, elongation at the break, and crystallinity of nanocomposites were improved compared to pristine PCL. Osteoblast cells were used to measure the cytotoxicity of PCL/fCNO nanocomposites. The in vitro biocompatibility measurements reveal that cell viability, adhesion, and cell growth were improved at $0.5 \mathrm{wt} \%$ of $\mathrm{f}$-CNOs, which signifies a positive effect of $\mathrm{f}-\mathrm{CNO}$ on osteoblast cells.

\section{Results and discussion}

To achieve good physicochemical properties of f-CNO-based nanocomposites, it is primarily vital to disperse the $\mathrm{CNO}$ particles throughout the polymer matrix uniformly, which is achieved in the current study by using the probe sonication (sonochemistry) method. Probe sonication is a simple, easy, and short-time physicochemical method that depends on highintensity ultrasound [32, 33]. Ultra probe-sonication depends on the acoustic cavitation phenomenon. Acoustic cavitation occurs in the liquid environment due to the fluctuation of pressure, which generates bubble growth, followed by bubble collapse and internal turbulence. Finally, this ultrasound energy converts into high temperature and confined pressure. Ultrasound waves exchange through carbon nanoparticles (CNOs), which are held by Van der Waals forces, and/or $\pi-\pi$ stacking. 
In this method, CNOs are arranged in a liquid environment. Colloidal stabilization of CNOs is achieved by the physisorption of PMPMA chains onto the CNO surface. Therefore, probe sonication would be a good method to produce uniformly dispersed and stabilized CNOs in aqueous environments or organic solvents. These colloidal stabilized CNOs are highly efficient to upgrade the electrical, tensile, and elasticity properties of the nanocomposites. Figure 1 shows the fabrication method of the PCL/f-CNO nanocomposite sheet and osteoblast cell growth. Initially, pure f-CNOs and PCL were probe-sonicated to obtain a uniform suspension of $\mathrm{PCL} / \mathrm{f}-\mathrm{CNO}$ composites. The resulted black mixture was oven-dried for $12 \mathrm{~h}$. The dried black mixture was subjected to hydraulic pressing to provide PCL/f-CNO nanocomposite sheets (Fig. 1). In addition, live/dead cell growth was studied with osteoblast cells, and more than $98 \%$ of live cells were observed (Fig. 1). This indicates the good biocompatibility of functionalized CNOs to the bone cells. Biocompatibility is the primary characteristic of medical grade materials for orthopedic implantation.

The microstructure of fractured PCL/f-CNO nanocomposites was measured using scanning electron microscopy (SEM) analysis, and the SEM images are illustrated in Fig. 2. As shown in Fig. 2(a), the fracture surface of the PCL/f-CNOs (0.2 wt\%) displays irregular surfaces. It shows that $\mathrm{f}-\mathrm{CNO}$ are uniformly distributed within the PCL matrix. Also, PCL/f-CNO (0.5 wt\%) composites display a similar asymmetrical surface. Thus, the SEM analysis reveals that $\mathrm{f}$-CNOs are homogeneously dispersed and reinforced within the PCL chains. The uniform dispersion can enhance the mechanical and crystallinity properties of PCL. It is worth mentioning that the homogeneous dispersion of CNOs and HA nanoparticles throughout the polymer matrix could enrich the crystallinity and mechanical properties of polymers [27, 28, 34].

Figure 3(a) illustrates the roughness $(\mathrm{Ra})$ measurements of pure PCL and PCL/f-CNO nanocomposites. As shown in Fig. 3(a), PCL/f-CNO nanocomposites exhibit improved roughness compared to pristine PCL. Particularly, PCL/fCNOs $(0.2 \mathrm{wt} \%)$ showed $0.21 \mu \mathrm{m}$, and PCL/f-CNOs (0.5 wt\%) exhibited $0.38 \mu \mathrm{m}$ of roughness, whereas pure PCL revealed $0.12 \mu \mathrm{m}$ of roughness. Overall, PCL/f-CNOs (0.5 wt\%) exhibited the highest roughness values, which signifies the original flat surface of pristine PCL was interrupted by the inclusion of f-CNOs. The improved roughness of nanocomposites can trigger cell adhesion and cell growth on the surface of nanocomposites [13, 27, 28].

Table I presents the yield strength, tensile strength, elongation at the break, and Young modulus of pure PCL and PCL/f-CNO nanocomposites. Figure 3(b) and Table I unveil the enhancement in the mechanical properties of PCL with the inclusion of $\mathrm{f}-\mathrm{CNO}$. The Young modulus of pure PCL, PCL/f-CNOs (0.2 wt\%), and PCL/f-CNOs (0.5 wt\%) are

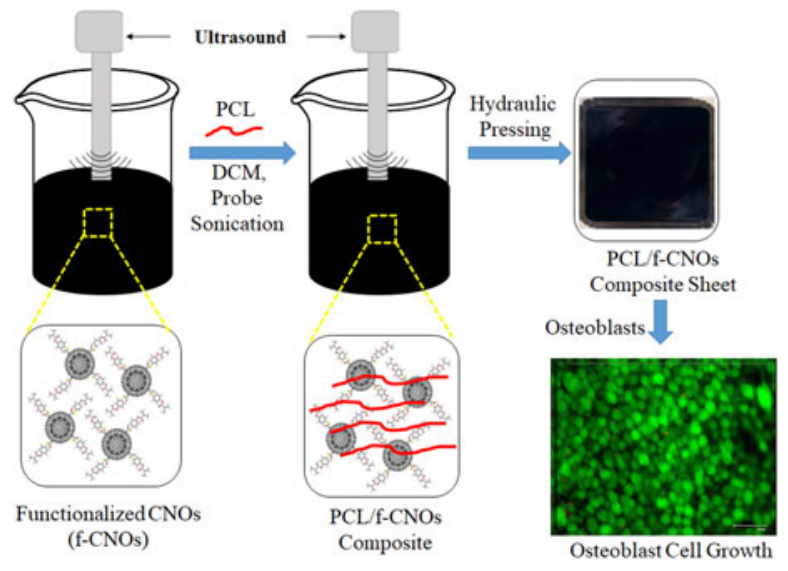

Figure 1: A schematic illustration showing the fabrication of $P C L / f-C N O$ nanocomposite sheets, and osteoblast cell growth.

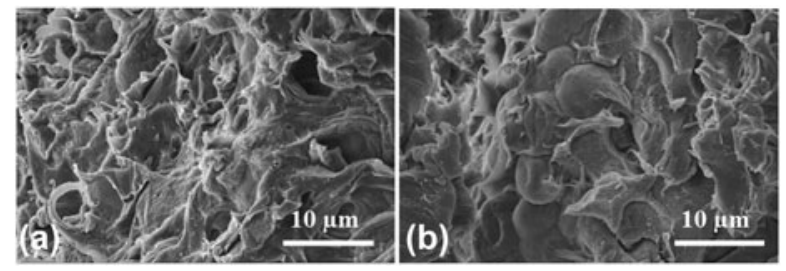

Figure 2: SEM micrograph of the fractured surfaces of (a) $\mathrm{PCL} / \mathrm{f}-\mathrm{CNO}$ (0.2 wt\%) and (b) PCL/f-CNO (0.5 wt\%) nanocomposites. Scale bar, $10 \mu \mathrm{m}$.

calculated to be $738.90,975.77$, and $1294.54 \mathrm{MPa}$, respectively. Similarly, yield strength also improved with the addition of $\mathrm{f}$ CNOs, particularly 12,18 , and $25 \mathrm{MPa}$ of yield strength was observed in pure PCL, PCL/f-CNOs (0.2 wt\%), and PCL/fCNOs (0.5 wt\%), respectively. The maximum enhancement in tensile strength up to $84 \mathrm{MPa}$ was attained with $0.5 \mathrm{wt} \%$ of $\mathrm{f}$ CNO content, as compared to $45 \mathrm{MPa}$ in PCL. The elongation at break of composite samples was slightly provoked by the addition of f-CNOs, as shown in Table I. The tensile results demonstrated that 2.1-fold of stiffness was upgraded in PCL/fCNO (0.5 wt\%) nanocomposites compared to pure PCL. Overall, the inclusion of $\mathrm{f}-\mathrm{CNO}$ s enriched the mechanical properties of PCL. It was presumed that due to the tensile force, pure PCL and f-CNOs strained to provide the shuffled alignment. The improved tensile properties demonstrate the uniform dispersion of $\mathrm{f}-\mathrm{CNO}$ within the PCL matrix. Besides, during the tensile test, external force might have been transferred between f-CNOs and the PCL matrix. This phenomenon could be due to the Van der Waals attractions or $\pi-\pi$ interactions between $\mathrm{f}-\mathrm{CNO}$ and PCL chains. Overall, the mechanical properties of nanocomposites revealed that with the inclusion of $\mathrm{f}$-CNOs, the tensile properties of PCL/f-CNO composites have improved, which is one of the basic and vital characteristics of orthopedic devices. The mechanical results were consistent with the previous report [27]. 


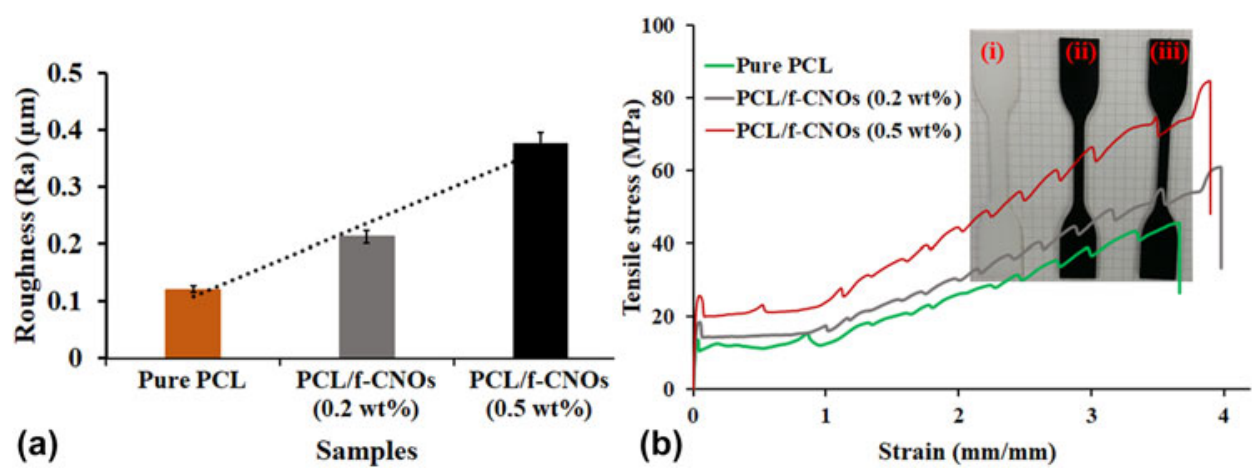

Figure 3: (a) Roughness and (b) tensile curves of neat $\mathrm{PCL}$ and $\mathrm{PCL} / \mathrm{f}-\mathrm{CNO}$ nanocomposites, respectively. (i), (ii), and (iii) indicate a tensile specimen of pure PCL, $\mathrm{PCL} / \mathrm{f}-\mathrm{CNOs}(0.2 \mathrm{wt} \%)$, and PCL/f-CNOs (0.5 wt\%), respectively.

TABLE I: Mechanical properties of pure PCL, and PCL/f-CNO composites. The data presented here are the average results of three specimens for each sample.

\begin{tabular}{lcccc}
\hline \hline Sample & $\begin{array}{c}\text { Yield } \\
\text { strength } \\
(\mathrm{MPa})\end{array}$ & $\begin{array}{c}\text { Tensile } \\
\text { strength } \\
(\mathrm{MPa})\end{array}$ & $\begin{array}{c}\text { Elongation } \\
\text { at break } \\
(\mathrm{mm} / \mathrm{mm})\end{array}$ & $\begin{array}{c}\text { Young's } \\
\text { modulus } \\
(\mathrm{MPa})\end{array}$ \\
\hline $\begin{array}{c}\text { Pure PCL } \\
\mathrm{PCL} / \mathrm{f}-\end{array}$ & $12.90 \pm 1.16$ & $41.20 \pm 0.89$ & $3.70 \pm 0.31$ & $738.90 \pm 3.76$ \\
$\begin{array}{c}\mathrm{CNOS}^{\mathrm{a}} \\
\mathrm{PCL} / \mathrm{f}-\end{array}$ & $18.20 \pm 1.10$ & $60.10 \pm 1.27$ & $3.98 \pm 0.77$ & $975.77 \pm 3.12$ \\
$\mathrm{CNOs}^{\mathrm{b}}$ & $25.44 \pm 0.79$ & $84.70 \pm 1.14$ & $3.89 \pm 0.19$ & $1294.54 \pm 2.32$ \\
\hline \hline
\end{tabular}

Data represent mean $\pm \mathrm{SD}(n=3$, Tukey's post hoc test). Statistically significant difference $(P<0.05)$ was observed between all test parameters of pure PCL, and PCL/f-CNO samples.

${ }^{\mathrm{a}} \mathrm{PCL} / \mathrm{f}-\mathrm{CNOs}(0.2 \mathrm{wt} \%)$.

${ }^{\mathrm{b}} \mathrm{PCL} / \mathrm{f}-\mathrm{CNOs}(0.5 \mathrm{wt} \%)$.

The thermal stability and decomposition behavior of neat $\mathrm{PCL}$ and PCL/f-CNO nanocomposites were measured using thermal gravimetric analysis (TGA). The initial temperature $\left(T_{0.1}\right)$ of onset degradation and the midpoint degradation temperature $\left(T_{0.5}\right)$ of weight loss of specimens are presented in Fig. 4(a). The PCL/f-CNO nanocomposites and pure PCL samples showed the thermal decomposition in the temperature range $345-462{ }^{\circ} \mathrm{C}$. As shown in Fig. 4(a), pristine PCL showed $T_{0.1}$ and $T_{0.5}$ approximately at $354^{\circ} \mathrm{C}$ and $368^{\circ} \mathrm{C}$, respectively. With the inclusion of $\mathrm{f}-\mathrm{CNO}$, the $\mathrm{PCL} / \mathrm{f}-\mathrm{CNO}$ nanocomposites showed increased onset degradation temperature. Specifically, PCL/f-CNO nanocomposites showed weight loss in the temperature range $370-460{ }^{\circ} \mathrm{C}$. Thermal degradation of the pure polymer occurred readily when the molecular chains had high mobility at the interface. However, thermal degradation of pure PCL was reduced with the inclusion of $\mathrm{f}-\mathrm{CNO}$ at the interface. This could be due to the mobility restriction of PCL chains at the interface. Overall, the TGA results reveal that the thermal stability of the nanocomposites was improved with the inclusion of $\mathrm{f}$-CNOs.

The DSC measurements can predict the polymer characteristics, including the melting temperature, degree of crystallinity, miscibility, and intermolecular interactions [13, 27]. Therefore, pure PCL and PCL/f-CNO nanocomposites were subjected to the DSC analysis, and the first heating, as well as cooling curves of all the samples, are illustrated in Fig. 4(b). The DSC results showed that the crystallinity of the nanocomposites was enhanced in the presence of $\mathrm{f}-\mathrm{CNO}$. The melting temperature of pristine PCL and PCL/f-CNOs was in the range of $57-61^{\circ} \mathrm{C}$. Generally, carbonaceous nanocomposites are a mixture of polymer chains and carbon materials that are not covalently attached. The nanocomposites display compatibility due to hydrogen bonding, dipole-dipole interactions, and other forces between the functional groups of the nanocomposites. Specifically, neat PCL exhibited the crystallization temperature $\left(T_{\mathrm{c}}\right)$ and melting temperature $\left(T_{\mathrm{m}}\right)$ approximately at $25.0^{\circ} \mathrm{C}$ and $57.0{ }^{\circ} \mathrm{C}$, respectively, whereas $\mathrm{PCL} / \mathrm{f}-\mathrm{CNO}(0.2 \mathrm{wt} \%$ ) nanocomposites showed $\left(T_{\mathrm{c}}\right)$ and $\left(T_{\mathrm{m}}\right)$ at around $26.7{ }^{\circ} \mathrm{C}$ and $58.1{ }^{\circ} \mathrm{C}$, respectively. Besides, $\mathrm{PCL} / \mathrm{f}-\mathrm{CNO}$ (0.5 wt\%) nanocomposites presented $\left(T_{\mathrm{c}}\right)$ and $\left(T_{\mathrm{m}}\right)$ at approximately $26.4{ }^{\circ} \mathrm{C}$ and $60.1{ }^{\circ} \mathrm{C}$, respectively. These DSC values are in agreement with the previous results [29].

The cell viability, cellular morphology, and LIVE/DEAD cell imaging of PCL/f-CNO nanocomposites were measured to check the cytotoxic influence of f-CNOs on the biocompatibility of nanocomposites. For this, human osteoblast cells were utilized to measure the cell viability of nanocomposites, and the results are presented in Fig. 5(a). The cells were cultured on the surface of neat PCL and PCL/f-CNO nanocomposites. As shown in Fig. 5(a), the cell viability of the nanocomposites was measured and compared with a control (tissue culture plate; TC). All the composite specimens exhibited approximately $70 \%$ of cell adhesion at day one post-seeding, whereas the TC plate showed around $95 \%$ of cell adhesion. On day one, neat PCL and PCL/f-CNO nanocomposites showed a similar cell adhesion. The cell viability was prominently influenced by cell adhesion, and the TC plate exhibited a somewhat higher cell number on day three. However, after seven and fourteen days of incubation, the cell viability was significantly 

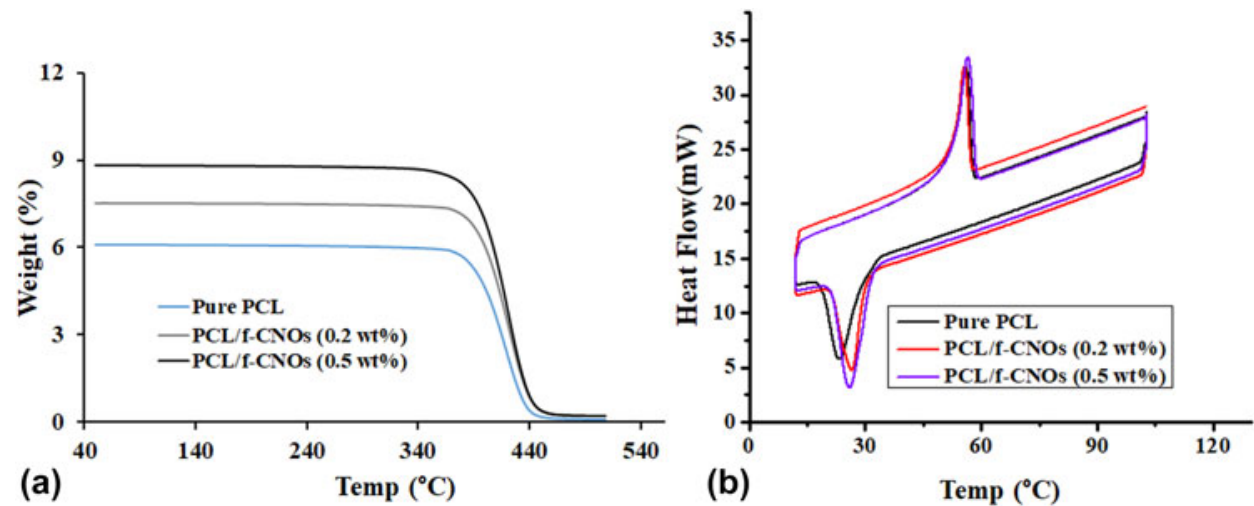

Figure 4: (a) TGA and (b) DSC curves of neat PCL and PCL/f-CNO nanocomposites, respectively.

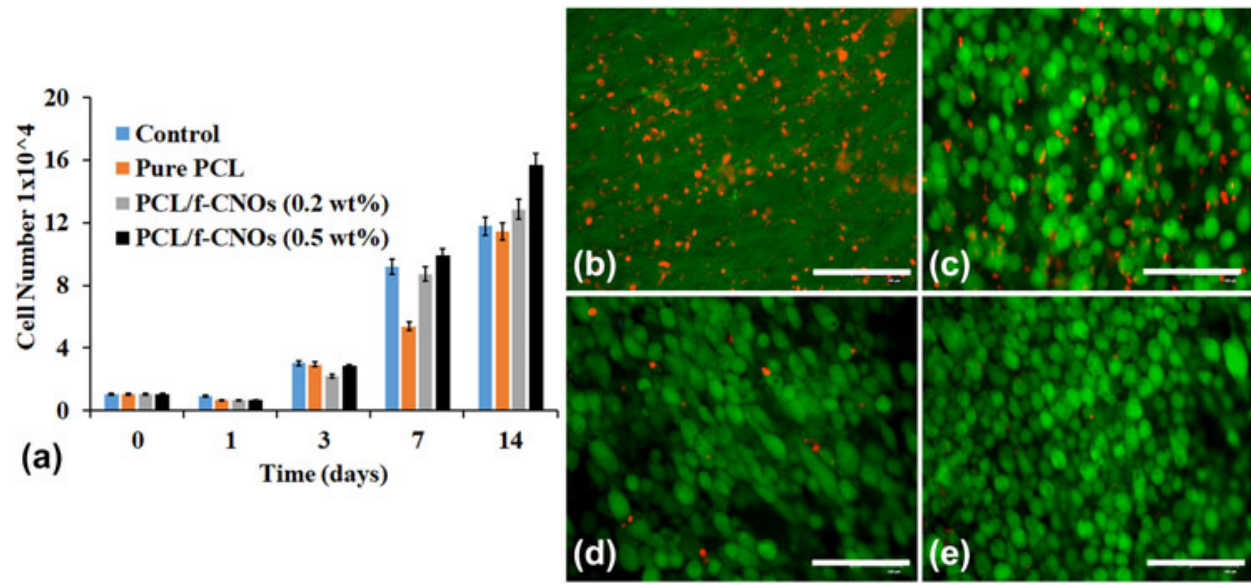

Figure 5: (a) Cell viability of the tissue culture plate (control), neat PCL, and PCL/f-CNO nanocomposites. Qualitative cell growth of osteoblast cells after fourteen days on (b) tissue culture well (control), (c) pure PCL, (d) PCL/f-CNOs ( 0.2 wt\%), and (e) PCL/f-CNOs (0.5 wt\%). The green color shows live cells, and the red color specifies dead cells. The scale bar is $100 \mu \mathrm{m}$.

improved in PCL/f-CNO nanocomposites. Besides, PCL/fCNO nanocomposites displayed a slightly higher proliferation rate than the control. Predominantly, PCL/f-CNO (0.5 wt\%) nanocomposites exhibited a $27 \%$ higher proliferation rate than the control for over fourteen days of study, which specifies a positive effect of $\mathrm{f}-\mathrm{CNO}$ on osteoblast cells. Thus, the cell viability results revealed that the $\mathrm{PCL} / \mathrm{f}-\mathrm{CNO}$ nanocomposites could support improved cell growth and have a positive influence on biocompatibility. Furthermore, the viability results also confirmed that conjugated CNOs are more biocompatible toward osteoblasts than CNT-UHMWPE nanocomposites [13].

In addition, osteoblast cell images were also measured using the LIVE/DEAD cell imaging kit. The osteoblast cells were cultured on the surface of nanocomposites for fourteen days, and the images were recorded using a fluorescence microscope [Figs. 5(b)-5(e)]. Red color indicates dead cells and green color indicates live cells. PCL/f-CNO (0.5 wt\%) composites showed more than $98 \%$ and PCL/f-CNO (0.2 wt\%) composites exhibited more than $91 \%$ of live cells. Insignificant fractions of dead cells were detected on the nanocomposites. Interestingly, flat- and stretched-shaped cells were observed on the surface of the nanocomposites [Figs. 5(b)-5(e)]. This could be due to the alignment of $\mathrm{f}-\mathrm{CNO}$ within the PCL matrix that could regulate the cell attachment. Similar results were observed with human mesenchymal stem cells on the pattern of isolated CNTs [30, 31].

An ideal bone-implant substitute should be appropriate for cell adhesion. The SEM analysis was performed to observe the cellular morphology and cellular adhesions to the PCL/fCNO (0.5 wt\%) nanocomposite scaffold. A typical overview of osteoblast cell morphology on the PCL/f-CNO (0.5 wt\%) composite specimen for 14 days is illustrated in Fig. 6a. The osteoblast cells cultured on the PCL/f-CNO sample showed flattened (green arrows) and spindle-shaped (yellow arrows) cells. The cells on the PCL/f-CNO (0.5 wt\%) nanocomposites exhibited fewer cytoplasmic extensions, and the cells were elongated in all directions on the composite surface. Pseudopodium-like structures (white arrow) were observed along 


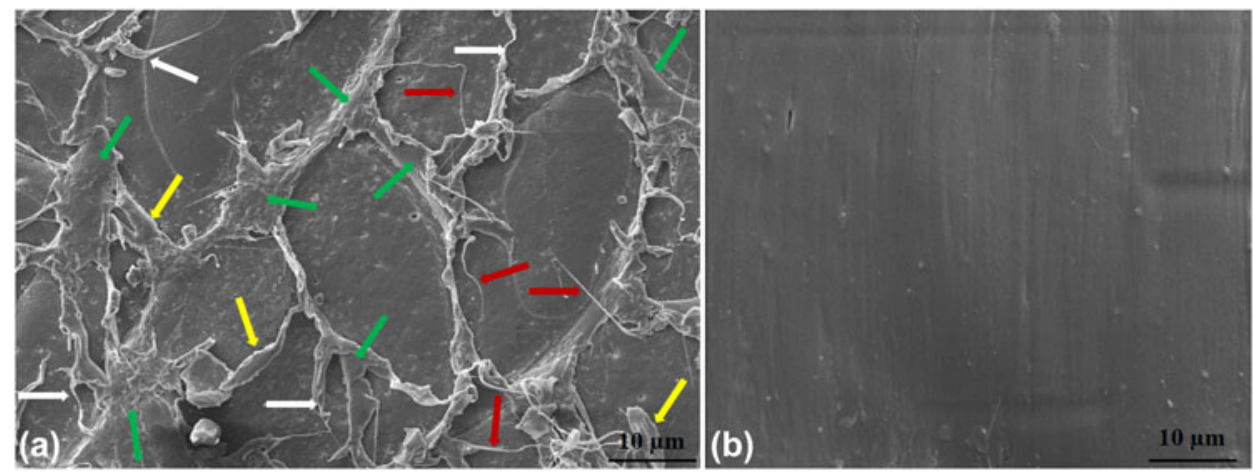

Figure 6: (a) An illustrative SEM image displays the morphology of osteoblast cells cultured for 14 days on the PCL/f-CNO (05 wt\%) composite surface. (b) The surface morphology of the PCL/f-CNO $(0.5 \mathrm{wt} \%)$ nanocomposite without cell culture treatment.

with many thin filopodia (red arrows) attached to the PCL/fCNO (0.5 wt\%) surface. For clarity, we have added the SEM image of the PCL/f-CNO (0.5 wt\%) composites without cell culture treatment as a blank sample [Fig. 6(b)] to see the morphological differences between the cell-cultured sample [Fig. 6(a)] and the blank sample. As seen in Fig. 6(b), without cellular growth, the surface of the blank sample was very smooth, which confirmed that the cells were attached to the surface of the PCL/f-CNO composites [Fig. 6(a)]. These results indicated that the PCL/f-CNO (0.5 wt\%) composites would be interesting for potential biomedical applications. The cell attachment results were consistent with the previous reports $[7,35,36,37]$.

\section{Conclusions}

Poly 4-mercaptophenyl methacrylate-carbon nano-onions (fCNOs) reinforced PCL/f-CNO nanocomposites were successfully fabricated using probe sonication followed by hydraulic pressing. The content of $\mathrm{f}$-CNOs was found to be critical for upgrading mechanical properties. Young's modulus of PCL was increased from 738.90 to $1294.54 \mathrm{MPa}$ at $\mathrm{PCL} / \mathrm{f}-\mathrm{CNO}$ $(0.5 \mathrm{wt} \%)$. A similar trend was noticed for tensile strength also, with a maximum of $80 \%$ improvement at $0.5 \mathrm{wt} \% \mathrm{f}-\mathrm{CNO}$ loading. Also, yield strength and elongation at the break of $\mathrm{PCL} / \mathrm{f}-\mathrm{CNO}$ nanocomposites were improved with the inclusion of $\mathrm{f}-\mathrm{CNO}$. The f-CNO concentration along with its colloidal dispersion and matrix reinforcement interfacial bonding was found to activate strengthening mechanisms. The biocompatibility of $\mathrm{f}-\mathrm{CNO}$ and $\mathrm{PCL} / \mathrm{f}-\mathrm{CNO}$ nanocomposites to osteoblast cells was found to be dose dependent. The PCL/fCNO (0.5 wt\%) nanocomposites exhibited more than $90 \%$ of cell viability and higher than $98 \%$ of survivability of bone cells on the surface of the PCL/f CNO (0.5 wt\%) nanocomposite. The current study suggests PCL/f-CNO nanocomposites would be considered as promising biomaterials for orthopedic applications and beyond.

\section{Experimental section}

\section{Materials and methods}

All the organic solvents and reagents were purchased from commercial suppliers and used without further purification. Polycaprolactone $\left(M_{\mathrm{w}} \sim 80,000\right), N$-hydroxysuccinimide (NHS), 1-ethyl-3-(3-dimethylaminopropyl) carbodiimide (EDC), 4(dimethylamino)pyridine (DMAP), and 2,2'-Azobis(2methylpropionitrile) (AIBN) were purchased from Sigma Aldrich (St. Louis, MO, USA). Osteoblast cells were procured from the American Type Culture Collection (ATCC, Manassas, VA). Dulbecco's modified Eagle's medium/F12 without phenol red (DMEM/F12), phosphate-buffered saline (PBS) ( $\mathrm{pH} 7.4)$, fetal bovine serum (FBS), penicillin/streptomycin, and trypsin were bought from Gibco Invitrogen (CA, USA). CellTiter96 ${ }^{\circledR}$ AQueous One Solution Cell Proliferation Assay was obtained from Promega (WI, USA). LIVE/DEAD Cell Imaging Kit was purchased from Molecular Probes, Life Technologies Corp. (CA, USA). Alizarin Red S, G418 disulfate salt, ascorbic acid, dexamethasone, $\beta$-glycerophosphate, and cetylpyridinium chloride were purchased from Sigma Aldrich (MO, USA).

\section{Fabrication of PCL/f-CNO nanocomposites}

The synthesis of PMPMA-CNOs was accomplished in good yield according to a previously reported protocol [27]. Two different concentrations of $\mathrm{f}-\mathrm{CNOs}(0.2 \mathrm{wt} \%$ and $0.5 \mathrm{wt} \%)$ were utilized to fabricate PCL/f-CNO nanocomposites. For this, fCNOs were probe-sonicated for $45 \mathrm{~min}$ in dichloromethane; then, PCL (45 grams) was added into the f-CNO solution, and probe sonication was continued for $120 \mathrm{~min}$ to accomplish a homogeneous black solution containing PCL-coated CNOs. After that, the black solution of PCL/f-CNOs was dried in a hot oven at $50{ }^{\circ} \mathrm{C}$ until it was completely dried. Then, the uniform black PCL/f-CNOs was loaded on $2 \mathrm{~mm}$ of stainless steel molds and placed in a CARVER 4122 hydraulic heating press at $120{ }^{\circ} \mathrm{C}$ followed by $24 \mathrm{MPa}$ pressure for $15 \mathrm{~min}$. After that, the pressure was released, 
and molds were cooled to room temperature to obtain PCL/ f-CNO nanocomposite sheets.

\section{Characterizations of PCL/f-CNO nanocomposites}

The morphological properties of synthesized PCL/f-CNOs were systematically characterized using scanning electron microscopy (SEM; ZEISS EVO ${ }^{\circledR}$ MA 25, Ostalbkreis, BadenWürttemberg, and Germany). PCL/f-CNO composite sheets were immersed in liquid nitrogen to fracture into small sections and gold-coated before measuring SEM images. The differential scanning calorimeter (DSC; TA Q2000, New Castle, DE) was used to measure the melting temperature and crystallinity of the nanocomposites at a scan rate of $10^{\circ} \mathrm{C} / \mathrm{min}$ with a temperature range of $25-120{ }^{\circ} \mathrm{C}$ under nitrogen atmosphere. The thermal gravimetric analysis (TGA; SDT Q600, TA Instruments) was used to measure the mass loss of the nanocomposites at a scan rate of $10{ }^{\circ} \mathrm{C} / \mathrm{min}$ with a temperature range of $25-600{ }^{\circ} \mathrm{C}$ under nitrogen atmosphere. The mechanical properties of the nanocomposites were recorded using a tensile testing machine (Instron 3365, Instron, and Norwood, MA) according to ASTM D 638. The size of the tensile sample was $33.0 \times 6.0 \times 2.0 \mathrm{~mm}$, and the crosshead speed was $50 \mathrm{~mm} /$ $\mathrm{min}$. The roughness $(\mathrm{Ra})$ of $\mathrm{PCL} / \mathrm{f}-\mathrm{CNO}$ nanocomposites was measured using the Mitutoyo profilometer (Mitutoyo, Guadalupe, Nuevo Leon, Mexico).

\section{Cytotoxicity evaluation of PCL/f-CNO nanocomposites}

Human osteoblast cells (bone-forming cells) were utilized to evaluate the biocompatibility or in vitro cytotoxicity of PCL/fCNO nanocomposites. The cytotoxicity of PCL/f-CNO nanocomposites was studied by culturing osteoblast cells on the surface of PCL/f-CNO (0.2 wt\%) and PCL/f-CNO (0.5 wt\%) nanocomposite samples. Additionally, cell viability and cell morphology were measured.

\section{Cell viability on $\mathrm{PCL} / \mathrm{f}-\mathrm{CNO}$ nanocomposites}

The cell viability was measured using the CellTiter $96{ }^{\circledR}$ AQueous One Solution Cell Proliferation Assay. Initially, disk-shaped ( $\sim 6.3 \mathrm{~mm}$ in diameter) specimens of pure PCL and PCL/fCNO composites were prepared to measure the proliferation and cell viability. Prior to the cell seeding, the disk-shaped specimens were sterilized with ethanol $(70 \% \mathrm{v} / \mathrm{v})$ followed by UV irradiation. Then, the specimens were cultured on 96-well plates, and osteoblast cells at a density of $1 \times 10^{4}$ cells per well $\left(\sim 3.12 \times 104 \mathrm{cells} / \mathrm{cm}^{-2}\right)$ were seeded over the specimens. On the next day, non-adherent cells were detached by changing the medium. Subsequently, the cell medium was rehabilitated every third day of the study. The cell number was measured using CellTiter $96^{\circledR}$ after 1, 3, 7, and 14 days post-seeding. Besides, the cell viability of the composites was measured using the LIVE/ DEAD Cell Staining Kit, and fluorescence microscopy was used to record the images. The tissue culture plate was used as a control in 96-well plates. The experiments were run in triplicate.

\section{Morphological evaluations of osteoblasts on PCL/f- CNO nanocomposites}

The disk-shaped (15.5 mm of diameter) PCL and PCL/f-CNO nanocomposite samples were cultured on 24-well plates, and osteoblast cells with a density of $1 \times 10^{4}$ cells $/ \mathrm{mL}$ were seeded on the surface of the samples in Dulbecco's modified Eagle's medium/F12 (DMEM/F12) supplemented with $2.5 \mathrm{mM}$ of Lglutamine, $0.3 \mathrm{mg} / \mathrm{mL}$ of G418 disulfate salt, $10 \%$ of fetal bovine serum, and $1 \%$ of penicillin/streptomycin. The cells were nurtured for $24 \mathrm{~h}$ in a $5 \% \mathrm{CO}_{2}$ atmosphere. Then, the medium was discarded from the wells and rinsed several times with phosphate buffer solution. After 14 days, cell images were recorded by an optical microscope (Model IN200A-5M, Amscope, Chino, CA).

\section{Cell attachment and morphology studies on PCL/f- CNO nanocomposites}

The cell culture measurements were conducted to quantify the cell attachment and cell proliferation of nanocomposites. The morphological topographies of osteoblast cells on the surface of nanocomposites were measured by SEM. For this, osteoblast cell-cultivated nanocomposite specimens were nurtured for 14 days. Next, the samples were washed with PBS and cured with $2.5 \%$ glutaraldehyde for $12 \mathrm{~h}$. After that, the specimens were dehydrated with ethanol and dried in a vacuum desiccator for $12 \mathrm{~h}$. The dried nanocomposite specimens were gold-coated prior to SEM analysis.

\section{Statistical analysis}

All the quantitative data were expressed as mean \pm standard deviations with $n=3$. Statistical analysis was performed by one-way analysis of variance (ANOVA) followed by Tukey's post hoc tests using Minitab17 (Minitab, State College, PA). The statistical significance was considered at $P \leq 0.05$.

\section{Acknowledgments}

We gratefully acknowledge Consejo Nacional de Ciencia y Tecnología de México and Tecnologico de Monterrey.

\section{References}

1. K. Alvarez and H. Nakajima: Metallic scaffolds for bone regeneration. Materials 2, 790 (2009). 
2. G. Manivasagam, D. Dhinasekaran, and A. Rajamanickam Biomedical implants: Corrosion and its prevention-A review. Recent Pat. Corros. Sci. 2, 40 (2010).

3. C.M. Agrawal: Reconstructing the human body using biomaterials. JOM 50, 31 (1998).

4. M. Niinomi: Recent metallic materials for biomedical applications. Metall. Mater. Trans. A 33, 447 (2002).

5. H.M. Wong, K.W.K. Yeung, K.O. Lam, V. Tam, P.K. Chu, K.D.K. Luk, and K.M.C. Cheung: A biodegradable polymer-based coating to control the performance of magnesium alloy orthopaedic implants. Biomaterials 31, 2084 (2010).

6. J.C. Middleton and A.J. Tipton: Synthetic biodegradable polymers as orthopedic devices. Biomaterials 21, 2335 (2000).

7. D.W. Hong, Z.T. Lai, T.S. Fu, T.T. Tsai, I.M. Chu, and P.L. Lai: The influences of polycaprolactone-grafted nanoparticles on the properties of polycaprolactone composites with enhanced osteoconductivity. Compos. Sci. Technol. 83, 64 (2013).

8. M. Assunta Basile, G. Gomez d'Ayala, M. Malinconico P. Laurienzo, J. Coudane, B. Nottelet, F.D. Ragione, and A. Oliva: Functionalized PCL/HA nanocomposites as microporous membranes for bone regeneration. Mater. Sci. Eng., C 48, 457 (2015).

9. S.I. Roohani-Esfahani, S. Nouri-Khorasani, Z. Lu, R. Appleyard, and $\mathbf{H}$. Zreiqat: The influence hydroxyapatite nanoparticle shape and size on the properties of biphasic calcium phosphate scaffolds coated with hydroxyapatite PCL composites. Biomaterials 31, 5498 (2010).

10. R. Cristescu, A. Doraiswamy, G. Socol, S. Grigorescu, E. Axente, D. Mihaiescu, A. Moldovan, R.J. Narayan, I. Stamatin, I.N. Mihailescu, B.J. Chisholm, and D.B. Chrisey: Dynamics of plume and crater formation after action of femtosecond laser pulse. Appl. Surf. Sci. 253, 6476 (2007).

11. H.R. Bakhsheshi-Rad, E. Hamzah, M. Kasiri-Asgarani, S. Jabbarzare, N. Iqbal, and M.R. Abdul Kadir: Deposition of nanostructured fluorine-doped hydroxyapatite-polycaprolactone duplex coating to enhance the mechanical properties and corrosion resistance of $\mathrm{Mg}$ alloy for biomedical applications. Mater. Sci. Eng., C 60, 526 (2016).

12. Q. Wang, H. Wang, Y. Wang, and F. Yan: The influences of several carbon additions on the fretting wear behaviors of UHMWPE composites. Tribol. Int. 93, 390 (2016).

13. N. Mamidi, H.M. Leija, J.M. Diabb, L.I. Romo, D. Hernandez, J.V. Castrejón, M.O. Romero, E.V. Barrera, and A.E. Zúñiga: Cytotoxicity evaluation of unfunctionalized multiwall carbon nanotubes-ultrahigh molecular weight polyethylene nanocomposites. J. Biomed. Mater. Res. 105, 3042 (2017).

14. A.I. Rezk, H.M. Mousa, J. Lee, C.H. Park, and C.S. Kim Composite PCL/HA/simvastatin electrospun nanofiber coating on biodegradable $\mathrm{Mg}$ alloy for orthopedic implant application. J. Coat. Technol. Res. 16, 477 (2019).

15. J.N. Coleman, U. Khan, and K. GunKo: Mechanical reinforcement of polymers using carbon nanotubes. Adv. Mater. 18, 689 (2006).
16. R. Alshehri, A.M. Ilyas, A. Hasan, A. Arnaout, F. Ahmed, and A. Memic: Carbon nanotubes in biomedical applications: Factors, mechanisms, and remedies of toxicity. J. Med. Chem. 59, 8149 (2016).

17. N.K. Mehra, K. Jain, and N.K. Jain: Pharmaceutical and biomedical applications of surface engineered carbon nanotubes. Drug Discovery Today 20, 750 (2015).

18. B. Zhang, P. Wei, Z.X. Zhou, and T.T. Wei: Interactions of graphene with mammalian cells: Molecular mechanisms and biomedical insights. Adv. Drug Delivery Rev. 105, 145 (2016).

19. D. Ugarte: Curling and closure of graphitic networks under electron-beam irradiation. Nature 359, 707 (1992).

20. F-D. Han and B. Yao: Yu-jun Bai preparation of carbon nanoonions and their application as anode materials for rechargeable lithium-ion batteries. J. Phys. Chem. C 115, 8923 (2011).

21. D. Pech, M. Brunet, H. Durou, P. Huang, V. Mochalin, Y. Gogotsi, P-L. Taberna, and P. Simon: Ultrahigh-power micrometer-sized supercapacitors based on onion-like carbon. Nat. Nanotechnol. 5, 651 (2010).

22. N. Keller, N.I. Maksimova, V.V. Roddatis, M. Schur, G. Mestl, Y.V. Butenko, V.L. Kuznetsov, and R. Schlögl: The catalytic use of onion-like carbon materials for styrene synthesis. Angew. Chem., Int. Ed. 41, 1885 (2002).

23. M. Frasconi, R. Marotta, L. Markey, K. Flavin, V. Spampinato, G. Ceccone, L. Echegoyen, E.M. Scanlan, and S. Giordani: Multifunctionalized carbon nano-onions as imaging probes for cancer cells. Chem. - Eur. J. 21, 19071 (2015).

24. M. Yang, K. Flavin, I. Kopf, G. Radics, C.H.A. Hearnden, G.J. McManus, B. Moran, A. Villalta-Cerdas, L.A. Echegoyen, S. Giordani, and E.C. Lavelle: Functionalization of carbon nanoparticles modulates inflammatory cell recruitment and NLRP3 inflammasome activation. Small 9, 4194 (2013).

25. A. Camisasca and S. Giordani: Carbon nano-onions in biomedical applications: Promising theranostic agents. Inorg. Chim. Acta $\mathbf{4 6 8}$ 67 (2017).

26. J. Luszczyn, M.E. Plonska-Brzezinska, A. Palkar, A.T. Dubis, A. Simionescu, D.T. Simionescu, B. Kalska-Szostko, K. Winkler, and L. Echegoyen: Small noncytotoxic carbon nano-onions: First covalent functionalization with biomolecules. Chem. - Eur. J. 16, 4870 (2010).

27. N. Mamidi, M.R. Martínez Gamero, J.V. Castrejón, and A.E. Zúníga: Development of ultra-high molecular weight polyethylene-functionalized carbon nano-onions composites for biomedical applications. Diamond Relat. Mater. 97, 107435 (2019).

28. N. Mamidi, A. González-Ortiz, I.L. Romo, and E.V. Barrera: Development of functionalized carbon nano-onions reinforced zein protein hydrogel interfaces for controlled drug release. Pharmaceutics 11, 621 (2019).

29. J.A. Simão, C.F. Bellani, and M.C. Branciforti: Thermal properties and crystallinity of PCL/PBSA/cellulose nanocrystals grafted with PCL chains. J. Appl. Polym. Sci. 134, 44493 (2017). 
30. J.R. Lee, S. Ryu, S. Kim, and B.S. Kim: Behaviors of stem cells on the carbon nanotube. Biomater. Res. 19, 19 (2015).

31. S. Namgung, K.Y. Baik, J. Park, and S. Hong: Controlling the growth and differentiation of human mesenchymal stem cells by the arrangement of individual carbon nanotubes. ACS Nano 5, 7383 (2011).

32. D.J. Flannigan and K.S. Suslick: Plasma formation and temperature measurement during single-bubble cavitation. Nature 434, 52 (2005).

33. J. Wu, Y.J. Zhu, S.W. Cao, and F. Chen: Hierarchically nanostructured mesoporous spheres of calcium silicate hydrate: Surfactant-free sonochemical synthesis and drug-delivery system with ultrahigh drug-loading capacity. Adv. Mater. 22, 749 (2010).

34. W. Noohom, K.S. Jack, D. Martin, and M. Trau:

Understanding the roles of nanoparticle dispersion and polymer crystallinity in controlling the mechanical properties of HA/PHBV nanocomposites. Biomed. Mater. 4, 015003

(2009).

35. A. Pae, H. Lee, H-S. Kim, Y-D. Kwon, and Y-H. Woo: Attachment and growth behaviour of human gingival fibroblasts on titanium and zirconia ceramic surfaces. Biomed. Mater. 4, 025005 (2009)

36. F. Otsuka, Y. Kataoka, and T. Miyazaki: Enhanced osteoblast response to electrical discharge machining surface. Dent. Mater. J. 31, 309-315 (2012).

37. M. Li, Q. Liu, Z. Jia, X. Xu, Y. Cheng, Y. Zheng, T. Xi, and S. Wei: Graphene oxide/hydroxyapatite composite coatings fabricated by electrophoretic nanotechnology for biological applications. Carbon 67, 185-197 (2014). 